Gut, 1987, 28, S1, 233-236

\title{
Characterisation of gastrin receptors on a rat pancreatic acinar cell line (AR42J). A possible model for studying gastrin mediated cell growth and proliferation
}

\author{
J L SCEMAMA, D FOURMY, A ZAHIDI, L PRADAYROL, C SUSINI \\ AND A RIBET
}

From INSERM U151, Bat $L_{3}$, CHU Rangueil, Toulouse, FRANCE

SUMMARY Trophic changes of the exocrine pancreas after in vivo gastrin (G)/CCK treatment are well documented but up to now the study of the mechanisms involved is restricted by the lack of a suitable in vitro model. Nevertheless the in vivo trophic effect induced by gastrin/CCK peptides has been associated with an increase of ornithine decarboxylase (ODC) activity. In the present work, using the AR42J cell line in which CCK receptors and stimulation of amylase release by CCK peptides has already been demonstrated, we investigated the presence of gastrin binding sites and the possible modulation of proliferation by an inhibitor of ODC activity. ${ }^{125} \mathrm{I}-\mathrm{BH}-\mathrm{G} 17 \mathrm{~ns}$ binding is saturable, reversible and specific. Potencies of the different analogues tested are G17ns $>\mathbf{C C K}_{8}$ $>\mathrm{CCK}_{8} \mathrm{~ns} \geqslant \mathrm{G}_{6} \mathrm{~s}>\mathrm{G} / \mathrm{CCK}_{4}$. Furthermore dBt cGMP, a non-peptide antagonist for CCK receptors, does not compete for gastrin binding. This indicates the existence of a subclass of gastrin binding sites. Difluoromethyl ornithine (DFMO) $(1 \mathrm{mM})$, an irreversible inhibitor of ODC, inhibits cell growth from day 3 up to day 7. This growth inhibition is dose dependent and closely related to an intracellular polyamine modulation. Putrescine and spermidine levels fell under detectable values while spermine levels increased. All these data suggest that this cell line could be a useful in vitro model to study the mechanisms of gastrin induced growth control.

Growth of the pancreatic tissue can be stimulated by gastrointestinal hormones such as cholecystokinin, gastrin, secretin, and analogues. ${ }^{2-4}$ Morisset and coworkers ${ }^{1}$ have recently demonstrated that caerulein induced pancreatic growth is associated with an increased accumulation of putrescine, spermidine and spermine, and that $\alpha$-Difluoromethyl ornithine (DFMO), an irreversible inhibitor of ornithine decarboxylase (ODC), can specifically inhibit caerulein induced pancreatic hypertrophy. These data lend further support to the involvement of ODC and polyamines in induced pancreatic growth, but up to now the study of the mechanisms involved is restricted by the lack of a suitable in vitro model.

In the present study using the AR42J cell line in which CCK receptors and stimulation of amylase release by CCK peptides have already been demonstrated, ${ }^{5}$ we investigated the presence of gastrin

Address for correspondence: Dr A Ribet, INSERM U151, Bat $\mathrm{L}_{3}$, CHU Rangueil, 31054 Toulouse Cedex, France binding sites and the possible modulation of cell proliferation by an inhibitor of ODC activity.

\section{Methods}

CELL CULTURE

AR42J cells, originally developed by Jessop and Hay, ${ }^{6}$ were obtained from Dr Logsdon (San Fransisco, California, USA). These cells were grown in Dulbecco's Modified Eagle Medium (DMEM) supplemented with $10 \%$ fetal calf serum. Cells were routinely plated at $2 \cdot 10^{5}$ cells $/ \mathrm{ml}$ into $60 \mathrm{~mm}$ well dishes and the medium changed every two days. Cell growth was measured by cell counting on a coulter counter coultronics model ZM.

\section{LIGAND BINDING STUDIES}

Non-sulphated gastrin 2-17 was radioiodinated by conjugation of the peptide to ${ }^{125}$ I-Bolton-Hunter reagent and purified by RP-HPLC as previously 
described. ${ }^{7}$ Binding assays were carried out on cells harvested with $0.025 \%$ EDTA alone. $2 \times 10^{5}$ cells were incubated with $60 \mathrm{pM}{ }^{125} \mathrm{I}-\mathrm{BH}-\mathrm{G}_{17}$ ns and various concentrations of analogues in a Krebs-Hepes buffer supplemented with $0.5 \%$ bovine serum albumin, $0.03 \%$ soybean trypsin inhibitor and $0.1 \%$ bacitracin, in a total volume of $0.5 \mathrm{ml}$ at $37^{\circ} \mathrm{C}$ for 30 min unless otherwise indicated in the Figures.

Dissociation kinetics were studied by incubating cells with the radioligand for the time required for equilibrium. Then, a saturable concentration of unlabelled peptide was added and residual binding was measured at various times. Specific binding was defined as the excess binding over that in blanks containing $1 \mu \mathrm{M}$ of unlabelled peptide.

\section{CELL POLYAMINE CONTENT}

Intracellular polyamines were extracted in $0.3 \mathrm{M}$ $\mathrm{HClO}_{4}$ and dansylated according to the procedure of Newton et al. ${ }^{8}$ Separation of the dansylated polyamines was carried out on a $\mu$ Bondapak $C_{18}$ column (Waters, Milford, USA) with a solvent composed of TEAP- $\mathrm{CH}_{3} \mathrm{CN}(\mathrm{pH} 3.5)$ in the ratio $(40: 60)$ for solvent A and (20:80) for solvent B. Samples were eluted in the gradient mode using the concave gradient program number 9 (Waters, model 660). The gradient changed from $100 \%$ solvent $A$ to $100 \%$ solvent $B$ in $15 \mathrm{~min}$ at a flow rate of $21 \mathrm{ml} / \mathrm{min}$. Fluorimetric detection used a model 420 (Waters) equipped with 280 and $338 \mathrm{~nm}$ filters for excitation and emission respectively. The area of the peaks was calculated on a Waters integrator Model 740 using a two point calibration curve.

${ }^{125} \mathrm{I}$-Bolton-Hunter reagent with a specific activity of $2000 \mathrm{Ci} / \mathrm{mmol}$ was purchased from Amersham, France. Acetonitrile was purchased from Fluka Lab.; Human gastrin-(2-17)ns from UCB Bioproducts, Brussels, Belgium; G/CCK-4 from Interchim, Montluçon, France, CCK-8 from CRB Laboratories, Cambridge, England; (Thr,Nle)-CCK ${ }_{9}$ was a gift from Professor E Wünsch, Max Planck Institut für Biochemie, München, West Germany. Putrescine, spermidine, spermine, DNS-Cl were purchased from Sigma (St Louis, Mo, USA). DFMO was kindly provided by Dr J Wilkins, Merrel Dow Research Institute (Strasbourg, France).

\section{Results}

\section{BINDING STUDIES}

As shown in Figure 1, specific binding of ${ }^{125} \mathrm{I}-\mathrm{BH}-(2-$ 17)-G-17ns to AR42J cells reached a maximal level after a $20 \mathrm{~min}$ incubation period $(94 \cdot 12 \pm 18 \cdot 6 \mathrm{fmol} /$ $10^{6}$ cells). Non-specific binding remained lower than $25 \%$ of total binding until $60 \mathrm{~min}$ of incubation. The addition of unlabelled G-17ns into the medium,

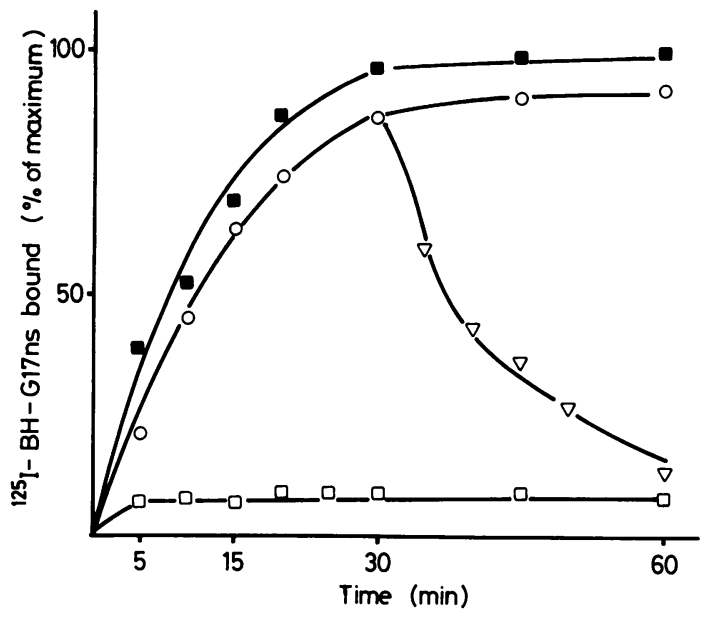

Fig. 1 Time course of association and dissociation of ${ }^{125} \mathrm{I}$ BH-G17ns to AR42J cells. Cells were incubated at $37^{\circ} \mathrm{C}$ with the radioligand alone ( $\square$ ), or in the presence of $1 \mu M$ $G_{17} n s$ (non specific binding) ( $\square$ ). At steady state $1 \mu M$ ( $\nabla) G_{17} n s$ was added to the incubation medium for dissociation. Results are expressed on the percentage of total radioactivity bound in the absence of unlabelled gastrin. Each value was determined in triplicate and this experiment is representative of three others.

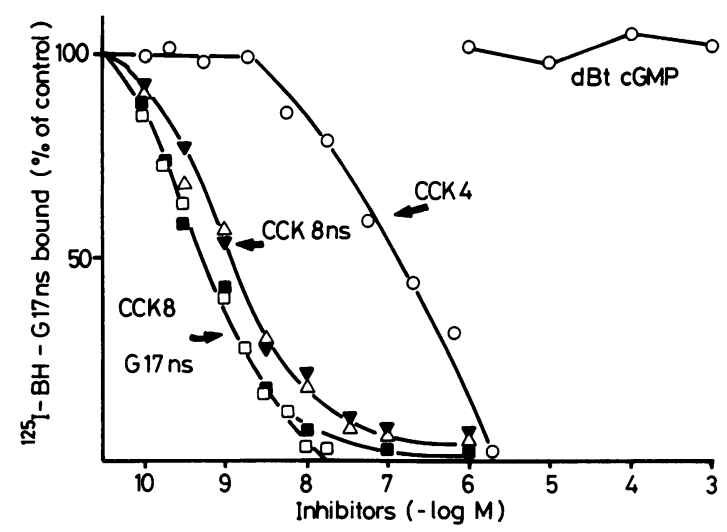

Fig. 2 Ability of various analogues to inhibit binding of ${ }^{125} \mathrm{I}-\mathrm{BH}-G_{17}$ ns to $A R 42 \mathrm{~J}$ cells. Cells were incubated for $30 \mathrm{~min}$ at $37^{\circ} \mathrm{C}$ with the radioligand $(60 \mathrm{pM})$ plus different concentration of $G_{17} n s(\square), C C K_{8}$ ( $), C C K_{8} n s(\nabla)$, $G_{6} s(\triangle), G / C C K_{4}(\bigcirc)$ and $d B t c G M P$. Results are the mean of at least five separate experiments.

resulted in rapid dissociation of bound radioactivity with a half time of about $8.5 \mathrm{~min}$. Analysis of the displacement curves of the labelled G-17ns by CCK and gastrin peptides showed that $\mathrm{CCK}_{8}$ and $\mathrm{G}_{17} \mathrm{~ns}$ inhibited the binding with the same potency (Fig. 2); $\mathrm{IC}_{50}$ were respectively $4 \cdot 2$ and $5 \cdot 610^{-10} \mathrm{M}$ and a total 


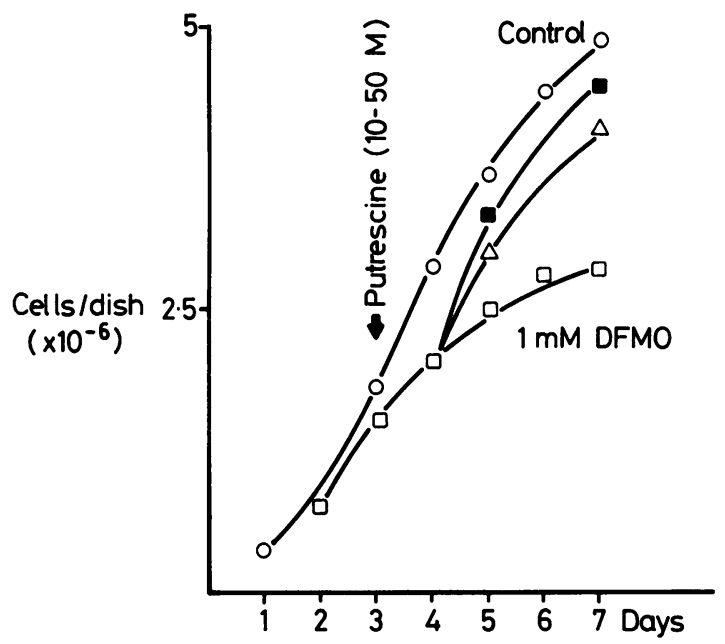

Fig. 3 Effects of DFMO on AR42J cell growth. AR42J cell number as a function of time, in the absence (O) or the presence of DFMO (1 mM) ( $\square)$. At day 3, putrescine $10 \mu \mathrm{M}(\triangle)$ or $50 \mu \mathrm{M}(\square)$ was added to the culture medium of cells treated with DFMO $1 \mathrm{mM}$. Results are the mean of four separate experiments done in triplicate.

inhibition was reached with $2 \cdot 10^{-8} \mathrm{M} . \mathrm{CCK}_{8} \mathrm{~ns}, \mathrm{G}_{6} \mathrm{~s}$ and $\mathrm{G} / \mathrm{CCK}_{4}$ also inhibited ${ }^{125} \mathrm{I}-\mathrm{BH}(2-17)-\mathrm{G}_{17}$ ns binding with $\mathrm{C}_{50}$ of $10^{-9} \mathrm{M}, 1.610^{-9}$ and $10^{-7} \mathrm{M}$ respectively. Dibutyryl cyclic GMP, a non-peptidic antagonist specific for CCK receptors, did not affect the radioligand binding (Fig. 2).

${ }^{125} \mathrm{I}-(\mathrm{Thr}, \mathrm{Nle})-\mathrm{CCK}_{9}$ binding results were in good agreement with those obtained by Logsdon ${ }^{5}$ using ${ }^{125} \mathrm{I}_{-} \mathrm{CCK}_{39}$ a radioligand. Furthermore we showed that gastrin peptide inhibited ${ }^{125} \mathrm{I}-(\mathrm{Th}, \mathrm{Nle})-\mathrm{CCK}_{9}$ binding with a high affinity and that dibutyryl cyclic GMP partially blocked $(60 \%)$ CCK binding at the highest dose tested $\left(10^{-3} \mathrm{M}\right)$.

The ratio gastrin preferring receptors $v$ CCKpreferring receptors was found to be $0 \cdot 107 \pm 0.011$.
AR42J cells, when grown in DMEM medium presented a logarithmic growth over a five day period with a population doubling time of 25-30 hours. Continuous treatment of AR42J cells with DFMO $(1 \mathrm{mM})$ produced growth inhibition from day 3 . The per cent inhibition was about $40 \%$ between days 5 and 7 in which growth seemed to be progressively arrested (Fig. 3). Viability of treated or control cells was tested by their ability to exclude trypan blue and was found to be higher than $95 \%$. Furthermore this growth inhibition was dose dependent and totally reversed when exogenous putrescine was added to the culture medium.

Intracellular polyamine contents were determined under the same experimental conditions (Table). In control cells, polyamines were raised in the first days of culture and reached basal values at day 3. DFMO $(0.5 \mathrm{mM})$ completely prevented the accumulation of putrescine and decreased spermidine content under $10 \%$ of control values. Spermidine level became undetectable for upper DFMO concentrations. This depletion was well correlated with growth inhibition. Spermine levels showed a two-fold increase during 1-5 mM DFMO treatment.

\section{Discussion}

The present study investigates the interaction of ${ }^{125} \mathrm{I}-$ BH-(2-17)-G17ns with a rat pancreatic acinar cell line (AR42J) and demonstrates the ability of DFMO to modulate cell growth and intracellular polyamine content.

${ }^{125} \mathrm{I}-\mathrm{BH}-(2-17)-\mathrm{G} 17 \mathrm{~ns}$ binding data indicated that gastrin receptor sites are present in AR42J cells. The ability of the different molecules tested to inhibit gastrin binding is similar to that found in dog pancreatic acini. ${ }^{7}$ In AR42J cells radioiodinated gastrin binds with a high affinity to specific sites, in contrast to that observed in rat acini. ${ }^{9} \mathbf{C C K}_{8}$ is about as potent as $\mathrm{G}_{17} \mathrm{~ns}$, whereas $\mathrm{CCK}_{8} \mathrm{~ns}, \mathrm{G}_{8}$ s and $\mathrm{CCK}_{4}$

Table Effect of DFMO treatment on the polyamine levels of cultured AR42J cells

\begin{tabular}{lccc}
\hline & \multicolumn{2}{c}{ Concentration (nmol/10 cells) } \\
\cline { 2 - 4 } Treatment & Putrescine & Spermidine & Spermine \\
\hline None & $0.144 \pm 0.015$ & $1.212 \pm 0.065$ & $0.473 \pm 0.004$ \\
DFMO $0.5 \mathrm{mM}$ & $<0.030$ & $0.157 \pm 0.05$ & $0.763 \pm 0.113$ \\
DFMO 1 mM & $<0.030$ & $<0.030$ & $1.114 \pm 0.174$ \\
DFMO $5 \mathrm{mM}$ & $<0.030$ & $<0.030$ & $0.992 \pm 0.143$ \\
DFMO $10 \mathrm{mM}$ & $<0.030$ & $<0.030$ & $1.150 \pm 0.259$ \\
DFMO 1 $\mathrm{mM}+$ & $<0.030$ & $1.316 \pm 0.461$ & $1.202 \pm 0.070$ \\
putrescine $10 \mu \mathrm{M}$ & & & \\
\hline
\end{tabular}

AR42J cells $\left(2 \cdot 10^{5}\right.$ cells $\left./ \mathrm{ml}\right)$ were plated and treated as described in materials and methods. At day $4,10 \mu \mathrm{M}$ putrescine were added in culture medium of cells treated with DFMO $1 \mathrm{mM}$ and, 24 hours later, cells were scraped out, counted and used for polyamine content determination. Results are the means \pm SEM of four separate experiments in duplicate. 
are less potent to inhibit the binding of labelled gastrin. Furthermore, dBtcGMP, a non-peptidic antagonist specific for CCK receptors, did not affect the binding of gastrin, whereas it inhibits $\mathbf{C C K}_{9}$ binding. All together these data suggest the existence of a subclass of CCK/gastrin binding sites displaying a high affinity for gastrin. These results are in agreement with those found by Logsdon ${ }^{5}$ who noted that CCK receptors in AR42J cells seemed to be different from those in normal rat pancreatic acini. Results obtained with DFMO indicate that AR42J cell growth depends on adequate intracellular polyamine concentration, and that AR42J cell line which possesses two classes of different binding sites for CCK and gastrin may represent a useful in vitro model for studying the mechanisms of CCK/gastrininduced growth control mediated by ODC activation.

\section{References}

1 Morisset J, Benrezzak O. Reversal of $\alpha$-difluoromethylornithine inhibition of caerulein-induce pancreatic growth by putrescine. Regulat Peptides 1985; 11 : 2018.
2 Dembinski AB, Johnson LR. Stimulation of pancreatic growth by secretin, caerulein and pentagastrin. Endocrinology 1980; 106: 323-8.

3 Morisset J. Stimulation of pancreatic growth by secretin and caerulein in suckling rats. Biomed Res 1980; 1: 405-9.

4 Solomon TE, Vanier M, Morisset J. Cell site and timecourse of DNA synthesis in pancreas after caerulein and secretin. Am J Physiol 1983; 245: G99-105.

5 Logsdon C. Glucocorticoids increase cholecystokinin receptors and amylase secretion in pancreatic acinar AR42J cells. J Biol Chem 1986; 261 : 2096-101.

6 Jessop NW, Hay RJ. Characteristics of two rat pancreatic exocrine cell lines derived from transplantable tumors. In vitro $1980 ; 16: 212$.

7 Fourmy D, Zahidi A, Pradayrol L, Vayssette J, and Ribet A. Relationship of CCK/gastrin receptor binding to amylase release in dog pancreatic acini. Regulat Peptides 1984; 10: 57-68.

8 Newton NE, Ohoro K, Abdel-Monem MM. Determination of diamine and polyamines in tissues by highpressure liquid chromatography. J Chromatogr 1976; 124: $277-85$

9 Sankaran H, Goldfine ID, Deveney CW, Wong KY, Williams JA. Binding of cholecystokinin to high affinity receptors on isolated rat pancreatic acini. J Biol Chem 1980; 255: 1849-53. 